See Article page XXX.

\section{Commentary: Short-term pain, long-term gain with left ventricular function after mitral valve repair}

\author{
Clancy W. Mullan, MD, and Arnar Geirsson, MD
}

Mitral regurgitation is a common disorder with serious consequences for patient morbidity, including arrhythmias, heart failure, and stroke, as well as mortality. ${ }^{1}$ For acceptable-risk patients with severe, symptomatic disease or evidence of left ventricular (LV) dysfunction, surgical repair at a center of excellence is widely accepted as the gold standard therapy ${ }^{2}$; however, no formal recommendations for optimal repair strategies exist, likely due to the multiple and complex phenotyping of primary mitral valve disease. The Canadian Mitral Research Alliance CardioLink-2 (CAMRA-2) trial was designed to evaluate differences in mitral valve function after leaflet-preserving versus leaflet-resecting techniques, with no observed differences between strategies. ${ }^{3}$ Hibino and colleagues ${ }^{4}$ report a subanalysis of the CAMRA-2 trial to investigate potential phased recovery of the LV and timeline of LV ejection fraction (EF) improvement after mitral valve repair, aiming to inform the conflicting evidence that had previously existed. ${ }^{5-7}$

The authors evaluated LV echocardiographic parameters and describe 2 phases of LV recovery after mitral repair. Independent of leaflet resection or preservation in their cohort, the LV demonstrated a decreased EF with improved forward stroke volume and end diastolic volumes. Over the subsequent year, the EF improved, albeit not to baseline. Although not improved at discharge, systolic parameters recovered over the following year. ${ }^{4}$

\footnotetext{
From the Division of Cardiac Surgery, Department of Surgery, Yale School of Medicine, New Haven, Conn.

Disclosures: Dr Geirsson has financial relationships with Medtronic and Edwards Lifesciences. Dr Mullan reported no conflicts of interest.

The Journal policy requires editors and reviewers to disclose conflicts of interest and to decline handling or reviewing manuscripts for which they may have a conflict of interest. The editors and reviewers of this article have no conflicts of interest.

Received for publication Sept 11, 2021; revisions received Sept 11, 2021; accepted for publication Sept 13, 2021.

Address for reprints: Arnar Geirsson, MD, Division of Cardiac Surgery, Yale School of Medicine, New Haven, CT 06510 (E-mail: arnar.geirsson@yale.edu).

J Thorac Cardiovasc Surg 2021; $\mathbf{\square}: 1-2$

0022-5223/\$36.00

Copyright (c) 2021 Published by Elsevier Inc. on behalf of The American Association for Thoracic Surgery

https://doi.org/10.1016/j.jtcvs.2021.09.021
}

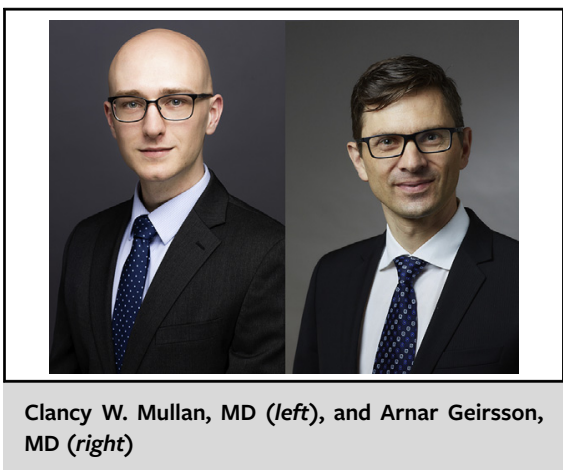

CENTRAL MESSAGE

Hibino and colleagues present a subanalysis of the CAMRA

CardioLink-2 trial, observing a

2-phased recovery of the left

ventricle: Early diastolic recovery

followed by late systolic

recovery.

The authors should be applauded for the limitations they acknowledge, which are insightful, thorough, and exemplary in their honest self-evaluation. Two should be highlighted. First, the authors acknowledge the wellcompensated nature of their population, which could limit generalizability. Although the observed EF of their population is similar to the real-world population of patients undergoing mitral repair, ${ }^{8}$ an interesting observation is a widening of the distribution of predischarge EF. Given the relevance of postrepair EF to late survival, ${ }^{9}$ detailed phenotyping, including biomarker profiling, ${ }^{10}$ of patients to describe those demonstrating a significant reduction in EF would provide valuable clinical insight, although this analysis is, of course, limited by its nature as a subanalysis of a completed clinical trial. Second, the choice of 2-dimensional echocardiography is a meaningful limitation compared with the more reproducible cardiac magnetic resonance imaging or 3-dimensional echocardiography. ${ }^{11}$ We are further limited by lack of information on whether or not imaging was contrasted.

Two additional observations are important for interpretation of the data. First, in the CAMRA-2 trial, twice as many patients in the resection group underwent concomitant coronary artery bypass. ${ }^{3}$ Second, the cardioprotection strategies employed by the trial are not described. Both may have influenced the observations described here. 
Hibino and colleagues ${ }^{4}$ provide valuable, hypothesisgenerating observations in their study, and they should be applauded for their efforts to inform a challenging and elusive question. Future studies to define patients likely to or to not demonstrate LV recovery after mitral repair should be conducted with more reliable imaging techniques, comprehensive phenotyping, and homogeneity of myocardial preservation.

\section{References}

1. Nishimura RA, Vahanian A, Eleid MF, Mack MJ. Mitral valve disease-current management and future challenges. Lancet. 2016;387:1324-34.

2. Otto CM, Nishimura RA, Bonow RO, Carabello BA, Erwin JP III, Gentile F, et al. 2020 ACC/AHA guideline for the management of patients with valvular heart disease: executive summary: a report of the American College of Cardiology/ American Heart Association Joint Committee on Clinical Practice Guidelines. J Am Coll Cardiol. 2021;77:450-500.

3. Chan V, Mazer CD, Ali FM, Quan A, Ruel M, de Varennes BE, et al. Randomized, controlled trial comparing mitral valve repair with leaflet resection versus leaflet preservation on functional mitral stenosis: the CAMRA CardioLink-2 study. Circulation. 2020;142:1342-50.
4. Hibino M, Dhingra NK, Verma S, Chan V, Quan A, Gregory AJ, et al. Mitral repair with leaflet preservation vs leaflet resection and ventricular reverse remodeling from a randomized trial. J Thorac Cardiovasc Surg. 2021;XX: $\mathrm{XX}-\mathrm{XXX}$.

5. Maffessanti F, Caiani EG, Tamborini G, Muratori M, Sugeng L, Weinert L, et al. Serial changes in left ventricular shape following early mitral valve repair. Am J Cardiol. 2010;106:836-42.

6. Le Tourneau T, Topilsky Y, Inamo J, Mahoney DW, Suri R, Schaff HV. Reverse left ventricular remodeling after surgery in primary mitral regurgitation: a volume-related phased process. Struct Heart. 2019;3:383-90.

7. Shafii AE, Gillinov AM, Mihaljevic T, Stewart W, Batizy LH, Blackstone EH. Changes in left ventricular morphology and function after mitral valve surgery. Am J Cardiol. 2012;110:403-8.e403.

8. Gammie JS, Chikwe J, Badhwar V, Thibault DP, Vemulapalli S, Thourani VH, et al. Isolated mitral valve surgery: the Society of Thoracic Surgeons Adult Cardiac Surgery Database analysis. Ann Thorac Surg. 2018;106:716-27.

9. Quintana E, Suri RM, Thalji NM, Daly RC, Dearani JA, Burkhart HM, et al. Left ventricular dysfunction after mitral valve repair-the fallacy of "normal" preoperative myocardial function. J Thorac Cardiovasc Surg. 2014;148: 2752-62.

10. Bäck M, Pizarro R, Clavel M-A. Biomarkers in mitral regurgitation. Prog Cardiovasc Dis. 2017;60:334-41.

11. Wood PW, Choy JB, Nanda NC, Becher H. Left ventricular ejection fraction and volumes: it depends on the imaging method. Echocardiography. 2014; 31:87-100. 